\title{
Um contributo para uma psicologia feminista crítica em Portugal
}

Amor, poder e violências na intimidade: os caminhos entrecruzados do pessoal e do político.

NEVES, Sofia.

Coimbra: Quarteto, 2008. 243 p.

Num país marcado pela falta de visibilidade dos saberes feministas, como é Portugal, a publicação do livro de Sofia Neves Amor, poder e violências na intimidade: os caminhos entrecruzados do pessoal e do político,' é de salientar. As razões para a importância desta obra são variadas. Começo por realçar a qualidade inequívoca dos percursos de investigação apresentados. $O$ trabalho de Sofia Neves, exemplar do ponto de vista da produção científica em psicologia de matriz construcionista social, ${ }^{2}$ possibilita importantes contribuições teóricas e metodológicas. Se, por um lado, aprofunda as metodologias feministas a que recorre, por outro, atribui-lhes um sentido estratégico e crítico, no modo como permitem o questionamento da veneração positivista pelo método, que tem caracterizado a psicologia.

Este sentido estratégico e crítico não é vácuo nem inócuo em relação às participantes nestes estudos. Pelo contrário, e em vez de enveredar pela mera discussão teórica, Sofia Neves coloca a psicologia ao serviço dos direitos humanos das mulheres, em vez de as tratar como meros objectos de estudo, aliando assim a 
Psicologia Social Crítica ${ }^{3}$ com as propostas da Psicologia Feminista, ${ }^{4}$ rompendo com a orientação positivista da disciplina.

Nascida a partir da implicação da autora com o pensamento feminista e a psicologia feminista crítica, a sua genealogia é outra, diferente de uma psicologia "malestream", 5 simultaneamente androcêntrica e centrada na idolatria do método experimental, e desatenta das relações de poder. ${ }^{6}$ Este trabalho traz as preocupações feministas como modo de enquadrar importantes questões societais, como a violência de género.

Marcado por um entendimento do modo como as relações de poder se estruturam na linguagem, o que a autora propõe é um olhar sobre o género enquanto relação social, e não como um atributo individual. Esta concepção do género fá-la entretecer as relações de poder enquanto constituintes das relações sociais e profundamente imbricadas nos modos como o género se instituiu enquanto ordem social. ${ }^{7}$

Estamos longe, quer das concepções assentes no sexo e da "biologia como destino", quer das prerrogativas das concepções clássicas assentes numa socialização da diferença, entendida como puramente simétrica. Nesta obra, o género ganha sentido enquanto conceito que permite um enquadramento das relações assimétricas de poder, entendidas no quadro de uma ordem social de género que Ihes dá plausibilidade, apesar de a inscrição social destas normas de género serem transvestidas de diferença biológica, como é amplamente demonstrado pelos estudos de género. ${ }^{8}$

Usando o amor como justificação, ${ }^{9}$ estas mulheres a que este livro dá voz sofreram violências desmedidas, acreditando que o amor trazia consigo esta consequência. Este amor sacrificial, consequência da ordem de género, transforma-as em vítimas. As vozes destas mulheres, que são infelizmente exemplos vivos da coerção imposta pela ordem de género, são neste livro escutadas e atendidas.

A análise detalhada que Sofia Neves faz das contribuições feministas para a prática psicológica permite-Ihe contribuir para um aumento importante dos conhecimentos na psicologia e actualizar estes conhecimentos, nomeadamente em Portugal, onde a psicologia feminista ainda é um domínio pouco visível da prática psicológica. ${ }^{10}$

A obra de Sofia Neves, fruto da sua tese de doutoramento em Psicologia Social na Universidade do Minho, orientada por Conceição
Nogueira, inscreve-se numa ruptura epistemológica e metodológica. Especificando um quadro de análise mais preocupado com a questão dos discursos que fundamentam a violência de género, há da parte da autora uma preocupação em situar, contextualizar, mas sobretudo desconstruir estas situações. Esta obra usa as propostas dos conhecimentos situados ${ }^{11}$ como modo de conceptualizar uma psicologia simultaneamente mais implicada e mais reflexiva. Centrada nas vivências destas mulheres, constrói uma tessitura analítica que the permite um enquadramento integrado das questões de género, poder, amor romântico e violência.

Igualmente, a ancoragem desta obra numa dimensão ética feminista e de intervenção reflexiva é determinante para mobilizar esforços para uma mudança social.

Trata-se, assim, de um texto interpelador e que se posiciona de forma preocupada, não apenas com a produção de conhecimento, mas também com imperativos éticos feministas, que reclama dos interventores e utilizadores da psicologia serem vectores de transformação social. Partindo de propostas partilhadas com a Psicologia da Libertação, ${ }^{12}$ o engajamento com a mudança social será uma das principais características da obra de Sofia Neves e das suas propostas para uma psicologia feminista crítica. Nesta obra, Sofia Neves conseguiu acumular mais conhecimentos, mas também mostrar possibilidades emancipatórias, revelando que ambos os princípios podem ser concretizados numa prática psicológica feminista.

\section{Notas}

' Este trabalho já foi inclusivamente reconhecido pelas Organizações Não Governamentais do Conselho Consultivo da Comissão para a Cidadania e Igualdade de Género, tendo-Ihe sido atribuído o Prémio Mulher Investigação "Carolina de Michaelis de Vasconcelos" 2006, o qual se destina a distinguir o melhor estudo de investigação e análise da situação das mulheres em Portugal.

${ }^{2}$ Conceição NOGUEIRA, 2001.

${ }^{3}$ Tomás IBAÑEZ e Lupicinio IÑIGUEZ, 1998.

${ }^{4}$ Mary GERGEN, 2001.

${ }^{5}$ Wendy HOLLWAY, 1989.

${ }^{6}$ Erika APFELBAUM, 1979[1999]. Ver também Lígia AMÂNCIO e João Manuel OLIVEIRA, 2006.

${ }^{7}$ Robert CONNELL, 2002.

${ }^{8} \mathrm{AMÂNCIO}, 1994$.

${ }^{9} \mathrm{NEVES}, 2007$.

${ }^{10}$ Conceição NOGUEIRA, Luísa SAAVEDRA e Sofia NEVES, 2006.

"Donna HARAWAY, 1988. Ver também OLIVEIRA e AMÂNCIO, 2006.

${ }^{12}$ Ignácio MARTIN-BARÓ, 1994. 


\section{Referências bibliográficas}

AMÂNCIO, Lígia. Masculino e feminino: a construção social da diferença. Porto: Afrontamento, 1994.

AMÂNCIO, Lígia; OLIVEIRA, João Manuel. "Men as Individuals, Women as a Sexed Category. Implications of Symbolic Asymmetry for Feminist Practice and Feminist Psychology." Feminism \& Psychology, v. 16, n. 1, 2006. p. 35-43.

APFELBAUM, Erika. "Relations of Domination and Movements for Liberation: An Analysis of Power between Groups (abridged)." Feminism and Psychology, v. 9, n. 3, 1979[1999]. p. 267-272.

CONNELL, Robert. Gender. Cambridge: Polity Press, 2002

GERGEN, Mary. Feminist Reconstructions in Psychology: Narrative, Gender and Performance. Thousand Oaks: Sage, 2001.

HARAWAY, Donna. "Situated Knowledges: The Science Question in Feminism and the Privilege of Partial Perspective." In: HARAWAY, Donna (ed.). Symians, Cyborgs and Women: The Reinvention of Nature. New York: Routledge, 1988[1991]. p. 183-202.

HOLLWAY, Wendy. Subjectivity and Method in Psychology: Gender, Meaning and Science. London: Sage, 1989.

IBAÑEZ, Tomás; IÑIGUEZ, Lupicinio. Critical Social Psychology. London: Sage, 1998.
MARTIN-BARÓ, Ignácio. Writings for a Liberation Psychology. Edited by Adrianne Aron and Shawn Corne. Cambribge, MA: Harvard University Press, 1994.

NEVES, Sofia. "As mulheres e os discursos genderizados sobre o amor: a caminho do 'amor confluente' ou o retorno ao mito do 'amor romântico'”? Revista Estudos Feministas, v. 15, n. 3, p. 609-627, 2007.

NOGUEIRA, Conceição. Um novo olhar sobre as relações sociais de género: feminismo e perspectiva crítica na psicologia social. Lisboa: Fundação Gulbenkian, 2001.

NOGUEIRA, Conceição, SAAVEDRA, Luísa, and NEVES, Sofia. "Critical (Feminist) Psychology in Portugal. Will it be possible?" In: DAFERMOS, Manolis, MARKAVIS, Athanasios, and TRILIVIA, Sofia (eds.). Annual Review of Critical Psychology, n. 5. [Disponível na internet: http:/ /www.discourseunit.com/arcp/5.htm]. 2006.

OLIVEIRA, João Manuel de; AMÂNCIO, Lígia. "Teorias feministas e representações sociais: desafios dos conhecimentos situados para a psicologia social". Revista Estudos Feministas, v. 14, n. 3, p. 597-615, 2006.

João Manuel de Oliveira Centro de Investigação e de Intervenção Social Instituto Superior de Ciências do Trabalho e da Empresa, Lisboa, Portugal 